\title{
Contents IMIA Yearbook of Medical Informatics 2018
}

\author{
President's Statement C. U. Lehmann \\ President's Statement \\ Obituary C. A. Kulikowski, R. Haux, N. M. Lorenzi, 0. Rienhoff \\ In Memoriam: Diarmuid Ua Conaill \\ Editorial J. H. Holmes, L. F. Soualmia, B. Séroussi \\ A 21 st Century Embarrassment of Riches: The Balance Between Health Data Access, Usage, and Sharing \\ IAHSI Paper R. Haux \\ Visions for IAHSI, the International Academy of Health Sciences Informatics \\ Keynote C. Petersen \\ Through Patients' Eyes: Regulation, Technology, Privacy, and the Future
}

Special Section:

Between Access and Privacy: Challenges in Sharing Health Data

Survey P. Shankar, N. Anderson

Advances in Sharing Multi-sourced Health Data on Decision Support Science 2016-2017

Working Group Contributions

\section{A. Georgiou, F. Magrabi, H. Hyppönen, Z. Shui-Yee Wong, P. Nykänen, P. J. Scott, E. Ammenwerth, M. Rigby}

The Safe and Effective Use of Shared Data Underpinned by Stakeholder Engagement and Evaluation Practice

M. Househ, R. Grainger, C. Petersen, P. Bamidis, M. Merolli

Balancing Between Privacy and Patient Needs for Health Information in the Age of

Participatory Health and Social Media: A Scoping Review

E.-H. Kluge, P. Lacroix, P. Ruotsalainen

Ethics Certification of Health Information Professionals

S. Kobayashi, T. B. Kane, C. Paton

The Privacy and Security Implications of Open Data in Healthcare

C. E. Kuziemsky, S. B. Gogia, M. Househ, C. Petersen, A. Basu

Balancing Health Information Exchange and Privacy Governance from a Patient-Centred Connected Health and Telehealth Perspective

Synopsis B. Malin, K. Goodman

Between Access and Privacy: Challenges in Sharing Health Data

Best Paper Selection Content summaries of:

Gilbert M, Bonnell A, Farrell J, Haag D, Bondyra M, Unger D, Elliot E. Click yes to consent: incorporating informed consent into an internet-based testing program for sexually transmitted and bloodborne infections. Int J Med Inform 2017;105:38-48

Humbert M, Ayday E, Hubaux JP, Telenti A. Quantifying interdependent risks in genomic privacy. ACM Transactions on Privacy and Security 2017;20(1):3

Ohno-Machado L, Sansone SA, Alter G, Fore I, Grethe J, Xu H, Gonzalez-Beltran A, Rocca-Serra P, Guraraj AE, Bell E, Soysal E, Zong N, Kim HE. Finding useful data across multiple biomedical data repositories using DataMed. Nat Genet 2017;49(6):816-9 
Section 1: Health Information Management

Survey

Wan Z, Vorobeychik Y, Xia W, Clayton EW, Kantarcioglu M, Malin B. Expanding Access to large-scale genomic data while promoting privacy: a game theoretic approach. Am J Hum Genet 2017;100(2):316-22 Yuan J, Malin B, Modave F, Guo Y, Hogan WR, Shenkman E, Bian J. Towards a privacy preserving cohort discovery framework for clinical research networks. I Biomed Inform 2017;66:42-51

Synopsis M. Bloomrosen, E. S. Berner

Findings from the 2017 on Health Information Management

Best Paper Selection Content summaries of:

Roehrs A, da Costa CA, da Rosa Righi R. OmniPHR: A distributed architecture model to integrate personal health records. J Biomed Inform 2017 Jul; 71:70-81

Klein DM, Pham K, Samy L, Bluth A, Nazi KM, Witry M, Klutts JS, Grant KM, Gundlapalli AV, Kochersberger G, Pfeiffer L, Romero S, Vetter B, Turvey CL. The Veteran-Initiated Electronic Care Coordination: A Multisite Initiative to Promote and Evaluate Consumer-Mediated Health Information Exchange. Telemed J E Health 2017 Apr;23(4):264-27

Boockvar KS, Ho W, Pruskowski J, DiPalo KE, Wong JJ, Patel J, Nebeker JR, Kaushal R, Hung W. Effect of health information exchange on recognition of medication discrepancies is interrupted when data charges are introduced: results of a cluster-randomized controlled trial. J Am Med Inform Assoc 2017 Nov 1;24(6):1095-101

Downing NL, Adler-Milstein J, Palma JP, Lane S, Eisenberg M, Sharp C; Northern California HIE Collaborative, Longhurst CA. Health information exchange policies of 11 diverse health systems and the associated impact on volume of exchange . J Am Med Inform Assoc 2017 Jan;24(1):113-22

Section 2: Human Factors and Organizational Issues

Survey

\section{K. A. Siek}

Expanding Human Computer Interaction Methods to Understand User Needs in the Design Process of Personal Health Systems

Synopsis S. Pelayo, J. Kaipio

Findings from the 2018 Yearbook Section on Human Factors and Organizational Issues

\section{Content summaries of:}

Ancker JS, Edwards A, Nosal S, Hauser D, Mauer E, Kaushal R, with the HITEC Investigators. Effects of workload, work complexity, and repeated alerts on alert fatigue in a clinical decision support system. BMC Med Inform Decis Mak 2017 Apr 10;17(1):36

Blijleven V, Koelemeijer K, Wetzels M, Jaspers M. Workarounds emerging from electronic health record system usage: consequences for patient safety, effectiveness of care, and efficiency of care. JMIR Hum Factors 2017 0ct 5;4(4):e27

Cresswell KM, Mozaffar H, Lee L, Williams R, Sheikh A. Safety risks associated with the lack of integration and interfacing of hospital health information technologies: a qualitative study of hospital electronic prescribing systems in England. BMJ Qual Saf 2017 Jul;26(7):530-41

Dufendach KR, Koch S, Unertl KM, Lehmann CU. A randomized trial comparing classical participatory design to VandAID, an interactive crowdsourcing plafform to facilitate user-centered design. Methods Inf Med 2017 0ct 26;56(5):344-9

Luna DR, Rizzato Lede DA, Otero CM, Risk MR, González Bernaldo de Quirós F. User-centered design improves the usability of drug-drug interaction alerts: experimental comparison of interfaces. I Biomed Inform 2017 Feb;66:204-13. 
Section 3: Clinical Information Systems

Survey M. M. Islam, T. Nasrin Poly, Y.-C. Li

Recent Advancement of Clinical Information Systems: Opportunities and Challenges

Synopsis W. O. Hackl, A. Hoerbst

On the Way to Close the Loop in Information Logistics: Data from the Patient - Value for the Patient

Best Paper Selection Content summaries of:

Andersen B, Kasparick M, Ulrich H, Franke S, Schlamelcher J, Rockstroh M, Ingenerf J.

Connecting the clinical IT infrastructure to a service-oriented architecture of medical devices. Biomed Tech 2018;63(1):57-68.

Nguyen P, Tran T, Wickramasinghe N, Venkatesh S. Deepr: A Convolutional Net for Medical Records. IEEE J Biomed Health Inform 2017;21(1):22-30

Olchanski N, Dziadzko MA, Tiong IC, Daniels CE, Peters SG, O'Horo JC, Gong MN. Can a Novel ICU Data Display Positively Affect Patient Outcomes and Save Lives? J Med Syst 2017;41:171.

Plastiras P, O'Sullivan DM. Combining Ontologies and Open Standards to Derive a Middle Layer Information Model for Interoperability of Personal and Electronic Health Records. J Med Syst 2017;41:195

Section 4: Sensor, Signal and Imaging Informatics

Survey

N. Ganapathy, R. Swaminathan, T. M. Deserno

Deep Learning on 1-D Biosignals: a Taxonomy-based Survey

Synopsis W. Hsu, T. M. Deserno, C. E. Kahn Jr.

Sensor, Signal, and Imaging Informatics in 2017

Best Paper Selection

Content summaries of:

Bote JM, Recas J, Rincon F, Atienza D, Hermida R. A modular low-complexity ECG delineation algorithm for real-time embedded systems. IEEE J Biomed Health Inform 2018;22(2):429-41

Grossmann P, Stringfield O, El-Hachem N, Bui MM, Rios Velazquez E, Parmar C, Leijenaar RT, Haibe-Kains B, Lambin P, Gillies RJ, Aerts HJ. Defining the biological basis of radiomic phenotypes in lung cancer. Elife 2017;6

Larson DB, Chen MC, Lungren MP, Halabi SS, Stence NV, Langlotz CP. Performance of a deep-learning neural network model in assessing skeletal maturity on pediatric hand radiographs. Radiology 2018;287(1):313-22

Satija U, Ramkumar B, Manikandan MS. Automated ECG noise detection and classification system for unsupervised healthcare monitoring. IEEE J Biomed Health Inform 2018;22(3):722-32 
IV

IMIA and Schattauer GmbH

Section 5: Decision Support

Survey I. Cho, D. W. Bates

Behavioral Economics Interventions in Clinical Decision Support Systems

Synopsis V. Koutkias, J. Bouaud

Contributions from the 2017 Literature on Clinical Decision Support

Best Paper Selection

Content summaries of:

Chen JH, Alagappan M, Goldstein MK, Asch SM, Altman RB. Decaying relevance of clinical data towards future decisions in data-driven inpatient clinical order sets. Int J Med Inform 2017 Jun;102:71-9

Ebadi A, Tighe PJ, Zhang L, Rashidi P. DisTeam: A decision support tool for surgical team selection. Artif Intell Med 2017 Feb;76:16-26

Fung KW, Kapusnik-Uner J, Cunningham J, Higby-Baker S, Bodenreider 0. Comparison of three commercial knowledge bases for detection of drug-drug interactions in clinical decision support. J Am Med Inform Assoc 2017 Jul 1;24(4):806-12

Mikalsen KØ, Soguero-Ruiz C, Jensen K, Hindberg K, Gran M, Revhaug A, Lindsetmo RO, Skrøvseth SO, Godtliebsen F, Jenssen R. Using anchors from free text in electronic health records to diagnose postoperative delirium. Comput Methods Programs Biomed 2017 Dec;152:105-14

Section 6: Knowledge Representation and Management

Survey

0. Bodenreider, R. Cornet, D. J. Vreeman

Recent Developments in Clinical Terminologies - SNOMED CT, LOINC, and RxNorm

Synopsis F. Dhombres, J. Charlet

As Ontologies Reach Maturity, Artificial Intelligence Starts Being Fully Efficient: Findings from the Section on Knowledge Representation and Management for the Yearbook 2018

Best Paper Selection Content summaries of:

Boudellioua I, Mahamad Razali RB, Kulmanov M, Hashish Y, Bajic VB, Goncalves-Serra E, Schoenmakers N, Gkoutos GV, Schofield PN, Hoehndorf R. Semantic prioritization of novel causative genomic variants. PLOS Comput Biol 2017;13(4):e1005500

Galeota E, Pelizzola M. Ontology-based annotations and semantic relations in large-scale (epi) genomics data. Brief Bioinform 2017;18(3):403-12

Khan Y, Saleem M, Mehdi M, Hogan A, Mehmood Q, Rebholz-Schuhmann D, Sahay R. SAFE: SPARQL Federation over RDF Data Cubes with Access Control. J Biomed Semantics 2017;8(1):5

Notaro M, Schubach M, Robinson PN, Valentini G. Prediction of Human Phenotype Ontology terms by means of hierarchical ensemble methods. BMC Bioinformatics 2017;18(1):449

Petegrosso R, Park S, Hwang TH, Kuang R. Transfer learning across ontologies for phenome-genome association prediction. Bioinformatics 2017;33(4):529-36 
Section 7: Consumer Health Informatics

and Education

Survey J. Huh, J. Koola, A. Contreras, A. KP. Castillo, M. Ruiz, K. G. Tedone, M. Yakuta, M. K. Schiaffino Consumer Health Informatics Adoption among Underserved Populations: Thinking beyond the Digital Divide

\section{Working Group Contribution}

H. Liyanage, S.-T. Liaw, E. Konstantara, F. Mold, R. Schreiber, C. Kuziemsky, A. L. Terry, S. de Lusignan

Benefit-risk of Patients' Online Access to their Medical Records: Consensus Exercise of an International Expert Group

Synopsis P. Staccini, A. Y. S. Lau

Findings from 2017 on Consumer Health Informatics and Education: Health Data Access and Sharing

Best Paper Selection

Content summaries of:

Bender JL, Cyr AB, Arbuckle L, Ferris LE. Ethics and Privacy Implications of Using the Internet and Social Media to Recruit Participants for Health Research: A Privacy-by-Design Framework for Online Recruitment. J Med Internet Res 2017 Apr 6; 19(4):e104

Sanderson SC, Brothers KB, Mercaldo ND, Clayton EW, Antommaria AHM, Aufox SA, Brilliant MH, Campos D, Carrell DS, Connolly J, Conway P, Fullerton SM, Garrison NA, Horowitz CR, Jarvik GP, Kaufman D, Kitchner TE, Li R, Ludman EJ, McCarty CA, McCormick JB, McManus VD, Myers MF, Scrol A, Williams JL, Shrubsole MJ, Schildcrout JS, Smith ME, Holm IA. Public Attitudes toward Consent and Data Sharing in Biobank Research: A Large Multi-site Experimental Survey in the US. Am I Hum Genet 2017 Mar 2;100(3):414-27

Peacock S, Reddy A, Leveille SG, Walker J, Payne TH, Oster NV, Elmore JG. Patient portals and personal health information online: perception, access, and use by US adults. J Am Med Inform Assoc 2017 Apr 1;24(el):el73-el77

Walker DM, Johnson T, Ford EW, Huerta TR. Trust Me, I'm a Doctor: Examining Changes in How Privacy Concerns Affect Patient Withholding Behavior. J Med Internet Res 2017 Jan 4;19(1):e2 
Section 8: Clinical Research Informatics

Survey N. C. Lea, J. Nicholls, N. K. Fitzpatrick

Between Scylla and Charybdis: Charting the Wicked Problem of Reusing Health Data for Clinical Research Informatics

Synopsis C. Daniel, D. Kalra

Clinical Research Informatics: Contributions from 2017

Best Paper Selection Content summaries of:

Caron A, Chazard E, Muller J, Perichon R, Ferret L, Koutkias V, Beuscart R, Beuscart JB, Ficheur G.

IT-CARES: an interactive tool for case-crossover analyses of electronic medical records for patient safety. J Am Med Inform Assoc 2017;24(2):323-30

Girardeau Y, Doods J, Zapletal E, Chatellier G, Daniel C, Burgun A, Dugas M, Rance B. Leveraging the EHR4CR platform to support patient inclusion in academic studies: challenges and lessons learned. BMC Med Res Methodol 28 2017;17(1):36

Huang J, Duan R, Hubbard RA, Wu Y, Moore JH, Xu H, Chen Y. PIE: A prior knowledge guided integrated likelihood estimation method for bias reduction in association studies using electronic health records data. J Am Med Inform Assoc 2017 Dec 1

Jackson RG, Patel R, Jayatilleke N, Kolliakou A, Ball M, Gorrell G, Roberts A, Dobson RJ, Stewart R. Natural language processing to extract symptoms of severe mental illness from clinical text: the Clinical Record Interactive Search Comprehensive Data Extraction (CRIS-CODE) project. BMJ Open 2017;7(1):e012012

Kim H, Bell E, Kim J, Sitapati A, Ramsdell J, Farcas C, Friedman D, Feupe SF, Ohno-Machado L. iCONCUR: informed consent for clinical data and bio-sample use for research. J Am Med Inform Assoc 2017;24(2):380-7

Section 9: Natural Language Processing

Survey

M. Filannino, 0̈. Uzuner

Advancing the State of the Art in Clinical Natural Language Processing through Shared Tasks

Synopsis A. Névéol, P. Zweigenbaum

Expanding the Diversity of Texts and Applications: Findings from the Section on Clinical Natural

Language Processing of the International Medical Informatics Association Yearbook

Best Paper Selection

Content summaries of:

Castro SM, Tseytlin E, Medvedeva 0, Mitchell K, Visweswaran S, Bekhuis T, Jacobson RS. Automated annotation and classification of BI-RADS assessment from radiology reports. J Biomed Inform 2017 May; 69:177-87

Pérez A, Weegar R, Casillas A, Gojenola K, Oronoz M, Dalianis H. Semi-supervised medical entity recognition: A study on Spanish and Swedish clinical corpora. J Biomed Inform 2017 Jul;71:16-30

Tapi Nzali MD, Bringay S, Lavergne C, Mollevi C, Opitz T. What Patients Can Tell Us: Topic Analysis for Social Media on Breast Cancer. JMIR Med Inform 2017 Jul 31;5(3):e23 
Section 10: Public Health and

Epidemiology Informatics

Survey

R. Gamache, H. Kharrazi, J. P. Weiner

Public and Population Health Informatics: The Bridging of Big Data to Benefit Communities

Synopsis R. Thiébaut, F. Thiessard

Artificial Intelligence in Public Health and Epidemiology

Best Paper Selection

Content summaries of:

Choi S, Lee J, Kang MG, Min H, Chang YS, Yoon S. Large-scale machine learning of media outlets for understanding public reactions to nation-wide viral infection outbreaks. Methods (2017) 129:50-59

Dernoncourt F, Lee JY, Uzuner 0, Szolovits P. De-identification of patient notes with recurrent neural networks. J Am Med Inform Assoc (2017) 24:596-606

Section 11: Cancer Informatics

Survey

E. Mathé, J. L Hays, D. G. Stover, J. L. Chen

The Omics Revolution Continues: The Maturation of High-Throughput Biological Data Sources

Synopsis J. L. Warner, D. A. Patt

Cancer Informatics in 2017: A New Beginning and a Bright Future

Best Paper Selection

Content summaries of:

Chakravarty D, Gao J, Phillips SM, Kundra R, Zhang H, Wang J, Rudolph JE, Yaeger R,

Soumerai T, Nissan MH, Chang MT, Chandarlapaty S, Traina TA, Paik PK, Ho AL, Hantash FM, Grupe A, Baxi SS, Callahan MK, Snyder A, Chi P, Danila D, Gounder M, Harding JJ, Hellmann MD, lyer G, Janiigian Y, Kaley T, Levine DA, Lowery M, Omuro A, Postow MA, Rathkopf D, Shoushtari AN, Shukla N, Voss M, Paraiso E, Zehir A, Berger MF, Taylor BS, Saltz LB, Riely GJ, Ladanyi M, Hyman DM, Baselga J, Sabbatini P, Solit DB, Schultz N. OncoKB: a precision oncology knowledge base. JCO Precis Oncol $2017 \mathrm{Jul} ; 2017$

Newton Y, Novak AM, Swatloski T, McColl DC, Chopra S, Graim K, Weinstein AS, Baertsch R, Salama SR, Ellrott K, Chopra M, Goldstein TC, Haussler D, Morozova O, Stuart JM. TumorMap: exploring the molecular similarities of cancer samples in an interactive portal. Cancer Res $2017 \mathrm{Nov}$ 1;77(21):e111-e114

Seyednasrollah F, Koestler DC, Wang T, Piccolo SR, Vega R, Greiner R, Fuchs C, Gofer E, Kumar L, Wolfinger RD, Winner KK, Bare C, Neto EC, Yu T, Shen L, Abdallah K, Norman T, Stolovitzky G, Soule HR, Sweeney CJ, Ryan CJ, Scher HI, Sartor O, Elo LL, Zhou FL, Guinney J, Costello JC, and Prostate Cancer DREAM Challenge Community. A DREAM Challenge to build prediction models for short-term discontinuation of docetaxel in metastatic castration-resistant prostate cancer. JCO Clin Cancer Inform 2017;1;1-15

F. González Bernaldo de Quirós, C. Otero, D. Luna

Terminology Services: Standard Terminologies to Control Health Vocabulary

K. C.Lun

The Datafication of Everything - Even Toilets

Research \& Education

C. U. Lehmann, A. V. Gundlapalli, J. J. Williamson, D. B. Fridsma, W. R. Hersh, M. Krousel-Wood, C. J. Ondrula, B. Munger

Five Years of Clinical Informatics Board Cerrification for Physicians in the United States of America

G. I. Mihalas, L. Stoicu-Tivadar

History of Romanian Medical Informatics: Learning from the Past to Reshape the Future 
Information on IMIA Welcome to IMIA 252

Honorary Fellows $\quad 255$

IMIA Member Societies 256

Institutional Members 257

Addresses of IMIA Member Societies $\quad 259$

Information on IMIA Regions Information on APAMI (Asia Pacific Association for Medical Informatics) 275

Information on Helina (African Region) 281

Information on IMIA-LAC (Federation of Health Societies in Latin America) 283

Information on MENAHIA (Middle East and North African Association for Health Informatics) 286

Information on NAMI (North-American Medical Informatics) 292

Information on EFMI (European Federation For Medical Informatics) 296

National Contribution P. Knaup, T. M. Deserno, H.-U. Prokosch, U. Sax

Implementation of a National Framework to Promote Health Data Sharing 302

$\begin{array}{llr}\text { Miscellaneous Contributors } & 305\end{array}$

$\begin{array}{ll}\text { Reviewers } & 306\end{array}$

$\begin{array}{ll}\text { IMIA Yearbook Special Topics } & 307\end{array}$ 